\title{
Legionella pneumophila IgM Antibody Measurement
}

National Cancer Institute

\section{Source}

National Cancer Institute. Legionella pneumophila IgM Antibody Measurement. NCI

Thesaurus. Code C92278.

The determination of the amount of Legionella pneumophila Ig M antibody present in a sample. 